Rwanda Journal of Medicine and Health Sciences Vol.3 No.1 March 2020 https://dx.doi.org/10.4314/rjmhs.v3i1.3

\title{
Clinical Profile of Paediatric Head and Neck Cancers at a Tertiary Hospital in Tanzania
}

Zephania Saitabau Abraham ${ }^{*}$, Enica Richard Massawe ${ }^{2}$, Aveline Aloyce Kahinga ${ }^{2}$, Kassim Babu Mapondella ${ }^{2}$, Willybroad Augustine Massawe ${ }^{3}$ Henry Swai ${ }^{3}$, Siwillis Mithe ${ }^{4}$, James Joseph Yahaya ${ }^{5}$, Daudi Ntunaguzi ${ }^{2}$

${ }^{1}$ Department of Surgery, University of Dodoma, College of Health and Allied Sciences, Dodoma, Tanzania

${ }^{2}$ Department of Otorhinolaryngology, Muhimbili University of Health and Allied Sciences, Dar es Salaam, Tanzania

${ }^{3}$ Department of Otorhinolaryngology, Muhimbili National Hospital, Dar es Salaam, Tanzania

${ }^{4}$ Department of Clinical Oncology, Muhimbili University of Health and Allied Sciences, Dar es Salaam, Tanzania

${ }^{5}$ Department of Anatomy and Histology, University of Dodoma, College of Health and Allied Sciences, Dodoma, Tanzania

*Correspondence: Zephania Saitabau Abraham. Department of Surgery-University of Dodoma, College of Health and Allied Sciences, Dodoma, Tanzania, PO. Box 259, Dodoma, Tanzania. Email:

zsaitabau@yahoo.com

\section{ABSTRACT}

\section{Background}

Paediatric head and neck cancers represent an important group of childhood cancers that require maximum attention at large. They are often diagnosed at advanced clinical stages at Muhimbili National Hospital (MNH).

\section{Objective}

To describe the clinical profile of paediatric head and neck cancers at a tertiary hospital in Tanzania

\section{Method}

A hospital based descriptive cross-sectional study was conducted involving 180 paediatric patients. Data were analyzed using SPSS program version 21 .

\section{Results}

A total of 180 paediatric patients were recruited where $61.1 \%$ were males and $38.9 \%$ were females. Majority belonged to the age group $0-5$ years $(53.9 \%)$. A total of 10 primary anatomical sites were found with the neck (cervical lymph node) predominating (36.1\%), followed by the orbit/eye $(34.4 \%)$ and the least anatomical sites were oral cavity $(1.1 \%)$ and parapharyngeal space $(0.5 \%)$. Leukocoria $(93.9 \%)$, red eye $(93.9 \%)$ and orbital cellulitis $(77.6 \%)$ predominated in retinoblastoma but in patients with lymphomas, predominant features were night sweats $(100 \%)$, weight loss $(100 \%)$ and fevers $(95.8 \%)$.

\section{Conclusion}

The clinical profile depicted in this study appears to correlate with advanced clinical stages.

Keywords: Paediatric; Head; Neck Cancers; Muhimbili; Tanzania

\section{INTRODUCTION}

Head and neck malignant neoplasms are cancerous neoplasms occurring in the nasal cavities, paranasal sinuses, nasopharynx, oral cavity, oropharynx, hypopharynx, larynx, ear, eye, scalp, orofacial bones, thyroid and salivary glands and they are reported to be the tenth most common cancer globally with associated potential morbidity and mortality.[1,2]
Malignant neoplasms are relatively rare in children unlike the pattern that is seen in older age groups.[3] In developed countries, paediatric cancers have been found to be second only to accidental trauma as a cause of death in children aged 5 to 14 years. [3,4] Contrary to what was observed in the past decades where cancers were reported to be rare in paediatric population in developing countries, the trend has now changed with studies showing an increasing incidence of head and neck cancers in these countries. Globally 
there is an estimated number of 650,000 new cases worldwide. According to the 2002 estimates of cancer incidence for the sub-Saharan Africa region, about half a million $(530,000)$ new cases of cancer occurred annually, 251,000 in males and 279,000 in females. In Tanzania, the prevalence of head and neck cancers was found to be $3 \%$ at MNH.[3-5,28]

The recent reports suggest that paediatric cancers are becoming a major source of mortality and therefore knowing the clinical features of such neoplasms is of paramount importance since it increases a high index of suspicion to clinicians who are encountering paediatric patients. This study was sought to describe the clinical features of head and neck malignant neoplasms in paediatric patients at $\mathrm{MNH}$ which is the country's tertiary hospital and has the largest paediatric oncology center.

\section{MATERIALS AND METHODS}

\section{Study design and participants}

This was a descriptive cross-sectional hospitalbased study which was conducted from June to November 2017 and included paediatric patients with histocytopathologically confirmed head and neck cancers at Muhimbili National Hospital.

\section{Study population}

The study included paediatric patients aged $\leq 18$ years with histocytopathologically confirmed head and neck malignant neoplasms whose parents/caretakers consented to participate in the study.

All paediatric patients aged $\leq 18$ years, both in patients and outpatients with histocytopathologically confirmed head and neck malignant neoplasms from the selected departments whose parents/care takers consented to participate were included in this study.

\section{Sampling method}

Convenient sampling method was utilized where paediatric patients from the selected departments and with histocytopathologically confirmed head and neck malignant neoplasms were recruited.

\section{Study Sample}

The sample size was calculated from Fischer's formula:

$\mathrm{n}=\left[\mathrm{Z}^{2} \mathrm{P}(1-\mathrm{P})\right] / \varepsilon^{2}$

where:

$\mathrm{n}=$ Minimum required sample size
$Z=1.96$ at $95 \%$ confidence interval which was assumed for the study

$\mathrm{P}=$ Proportion of those with the characteristic of interest which is the estimated proportion of paediatric head and neck malignant neoplasms which was $12 \%$ in children under the age of 19 years.[6]

$\varepsilon=$ Margin of error which was conventionally taken as the sampling error at 1.96 and was thus taken as $5 \%$ in this study.

Therefore, from the above formula the adjusted sample size used was 180 paediatric patients after considering non-response rate of $10 \%$

\section{Data collection methods and tools}

Pretested, interviewer administered structured questionnaires were tools used to collect data from selected patients. Age and sex of the targeted patients, clinical examination findings especially clinical features, topographical site of the malignant neoplasm and the histocytopathologically confirmed diagnosis were filled in the questionnaires. All histocytopathological specimens were processed and analysed by qualified histopathologist or cytologists working at Muhimbili National Hospital.

\section{Data analysis}

Data analysis was done using the Statistical Package for Social Sciences (SPSS) version 21. Quantitative variables were analyzed using mean, median and percentages. A two-tailed P-value $<0.05$ was considered significant.

\section{Ethical considerations}

Ethical clearance was sought from Research and Publication Committee of the School of Medicine of the Muhimbili University of Health and Allied Sciences. Administrative permission to conduct the study was obtained from MNH.

A written informed consent for children's participation in the study was obtained from parent/care taker(s) before enrolment of each child into the study.

\section{RESULTS}

\section{Sociodemographic characteristics of participants}

Of the 180 study participants, majority were males $110(61.1 \%)$ while females were $70 \quad(38.9 \%)$ $(\mathrm{M}: \mathrm{F}=1.57: 1)$, ( $\mathrm{p}$ value $=0.002)$ and mean age (years) was $1.64 \pm 0.768$. Majority of patients $97(53.9 \%)$ 
Rwanda Journal of Medicine and Health Sciences Vol.3 No.1 March 2020 https://dx.doi.org/10.4314/rjmhs.v3i1.3

were in the age group 0-5 years in both males $(43.6 \%)$ and females $(70 \%)$ while least number of patients $32(17.8 \%)$ belonged to the age group 1217 years. (Table 1 )

Table 1. Age and Sex distribution of paediatric patients with head and neck malignant neoplasms

\begin{tabular}{llll}
\hline $\begin{array}{l}\text { Age group } \\
\text { (years) }\end{array}$ & Sex & & \\
\cline { 2 - 3 } & Male (\%) & Female (\%) & Total (\%) \\
\hline $0-5$ & $48(43.6)$ & $49(70)$ & $97(53.9)$ \\
$6-11$ & $40(36.4)$ & $11(15.7)$ & $51(28.3)$ \\
$12-17$ & $22(20 \%)$ & $10(14.3)$ & $32(17.8)$ \\
Total & $110(61.1)$ & $70(38.9)$ & $180(100)$ \\
\hline
\end{tabular}

\section{Distribution of primary anatomical sites for paediatric head and neck malignant neoplasms}

A total of 10 anatomical sites were found in this study with majority having the neck (cervical neck nodes) 65 $(36.1 \%)$ as the primary site followed by the orbit/eye $62(34.4 \%)$. (Figure 1$)$

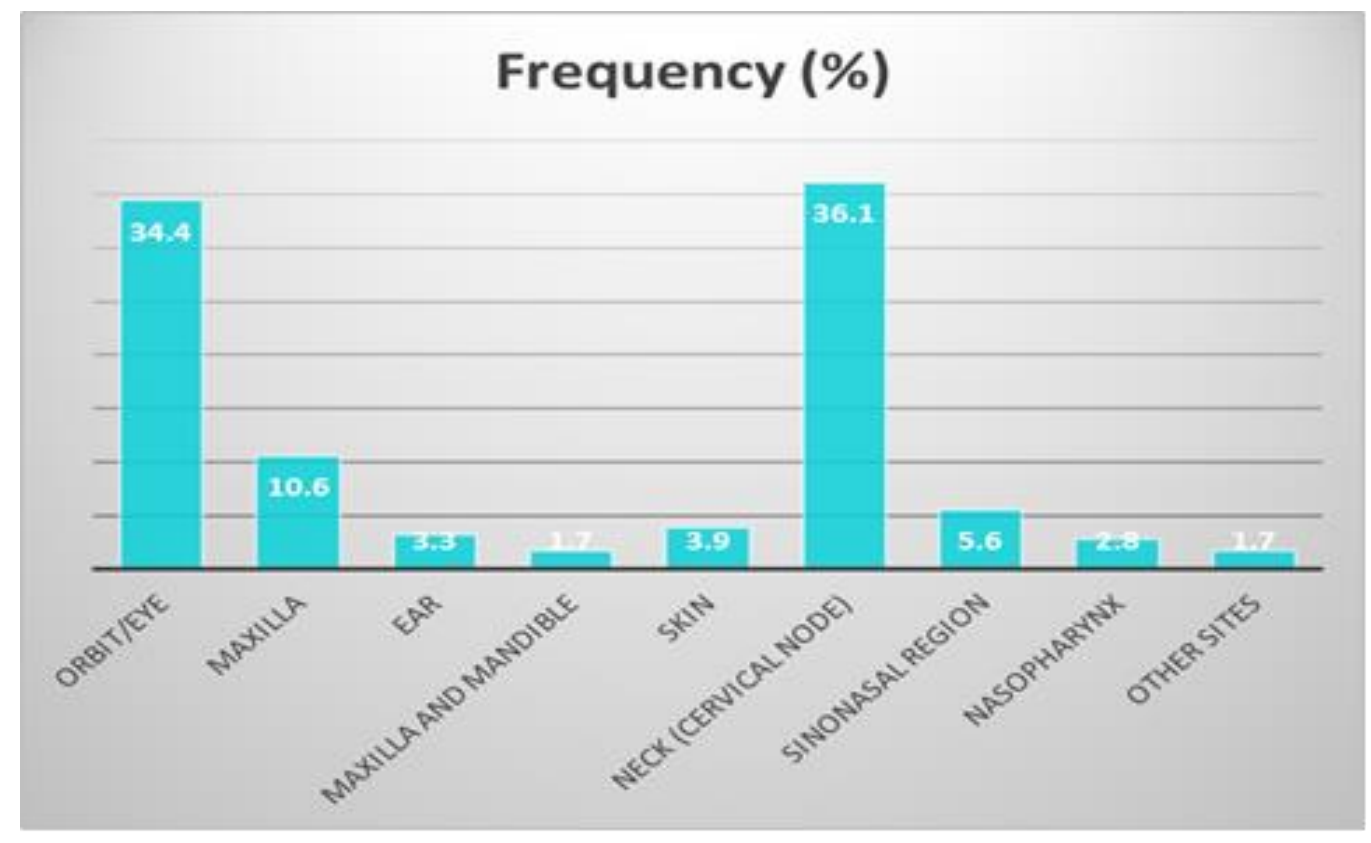

Figure 1: Distribution of primary anatomical sites for paediatric head and neck malignant neoplasms

Distribution of paediatric head and neck malignant neoplasms by primary anatomical sites and age of patients

In patients aged 0-5 years, the orbit/eye 56 (90.3\%) and other sites (parapharyngeal space and oral cavity) $3(100 \%)$ were predominantly affected and leastly the nasopharynx 1 (20\%). Among those aged 12-17 years, nasopharynx was the most affected
$(80 \%)$ site and leastly the neck (cervical nodes) $(24.6 \%)(P$-value $=0.000)($ Table 2$)$

Histocytopathological distribution of paediatric head and neck malignant neoplasms

From the study, the predominant variant was lymphoma $(52.8 \%)$ followed by retinoblastoma $(27.2 \%)$ whereas the least ones were olfactory neuroblastoma $1(1.1 \%)$ and Langerhans cell histiocytosis $1(0.6 \%)$ (Figure 2$)$ 


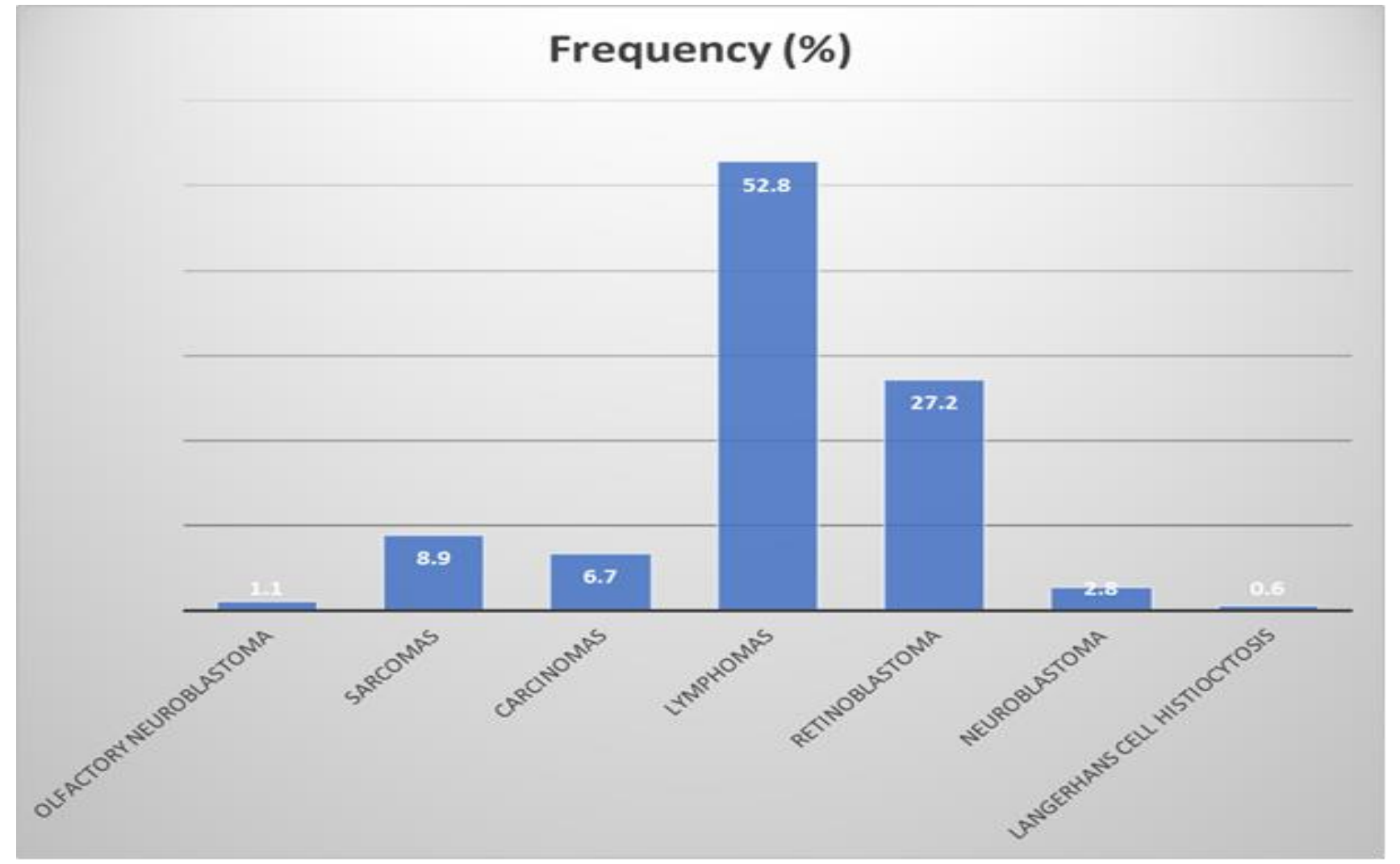

Figure 2. Histocytopathological distribution of paediatric head and neck malignant neoplasms

\section{Clinical features of sinonasal and nasopharyngeal cancers}

In this study, rhinological (100\%), facial swelling $(100 \%)$ and neck masses $(60 \%)$ predominated in sinonasal cancer. Patients with nasopharyngeal cancers were preoccupied with rhinological (100\%), otological (100\%), and neck masses (100\%). Central nervous system (10\% in sinonasal cancers and $20 \%$ in nasopharyngeal cancers) manifestations was the least reported clinical feature in such patients. (Table 2)

Table 2. Clinical features of sinonasal and nasopharyngeal cancers

\begin{tabular}{ccc}
\hline Clinical features & \multicolumn{2}{c}{ Type of head and neck cancer (\%) } \\
\cline { 2 - 3 } & $\begin{array}{c}\text { Sinonasal cancer } \\
(\mathbf{n}=\mathbf{1 0})\end{array}$ & $\begin{array}{c}\text { Nasopharyngeal } \\
\text { cancer (n=5) }\end{array}$ \\
\hline Rhinological & $10(100)$ & $5(100)$ \\
Otological & $1(10)$ & $5(100)$ \\
Dental & $3(30)$ & $4(80)$ \\
Cheek/Facial numbness & $3(30)$ & $1(20)$ \\
Central nervous system & $1(10)$ & $1(20)$ \\
manifestations & $9(90)$ & $5(100)$ \\
Ophthalmological & $10(100)$ & \\
Facial swelling & $6(60)$ & $4(80)$ \\
Neck mass & $7(70)$ & \\
Sinus tenderness & & \\
Miscellaneous features & &
\end{tabular}

\section{Clinical features of lymphomas}


Rwanda Journal of Medicine and Health Sciences Vol.3 No.1 March 2020 https://dx.doi.org/10.4314/rjmhs.v3i1.3

In this study, fevers $(100 \%$ in Hodgkin and $91.1 \%$ in non-Hodgkin lymphomas), night sweats $(90 \%$ in Hodgkin and $88.9 \%$ in non-Hodgkin lymphoma), neck masses $(96 \%$ in Hodgkin and $75.6 \%$ in nonHodgkin lymphoma) and weight loss $(90 \%$ in
Hodgkin and $88.9 \%$ in non-Hodgkin lymphoma) were the predominant features in lymphomas and none of the patients had distant metastasis. (Figure 3)

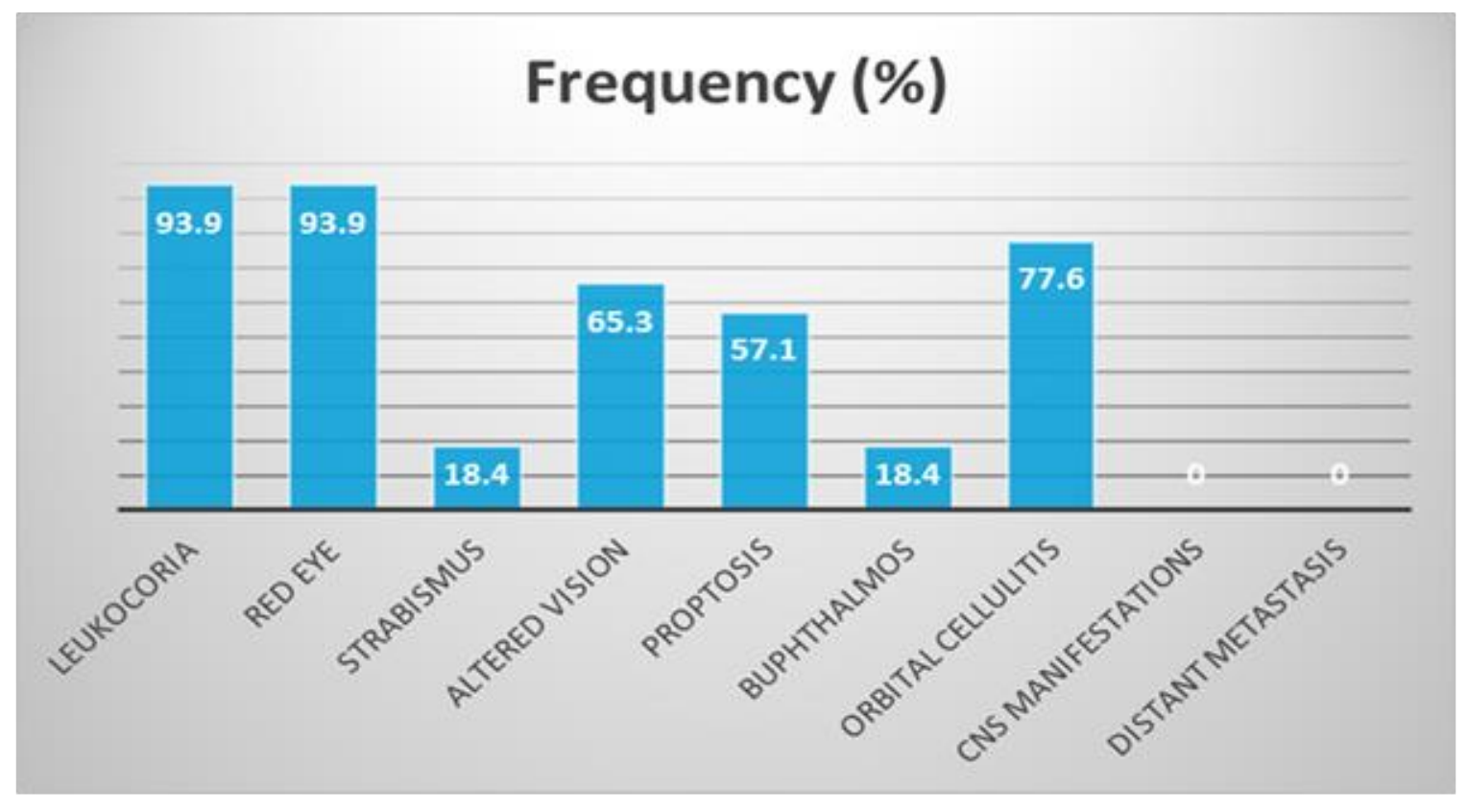

Figure 3. Clinical features of lymphomas $(n=95)$

\section{Clinical features of retinoblastoma}

In paediatric patients with retinoblastoma, the predominant features were leukocoria and red eye each accounting for $93.9 \%$ of cases and the least reported features were strabismus and buphthalmos each contributing for $18.4 \%$ of cases. (Figure 4) 


\section{Frequency (\%)}

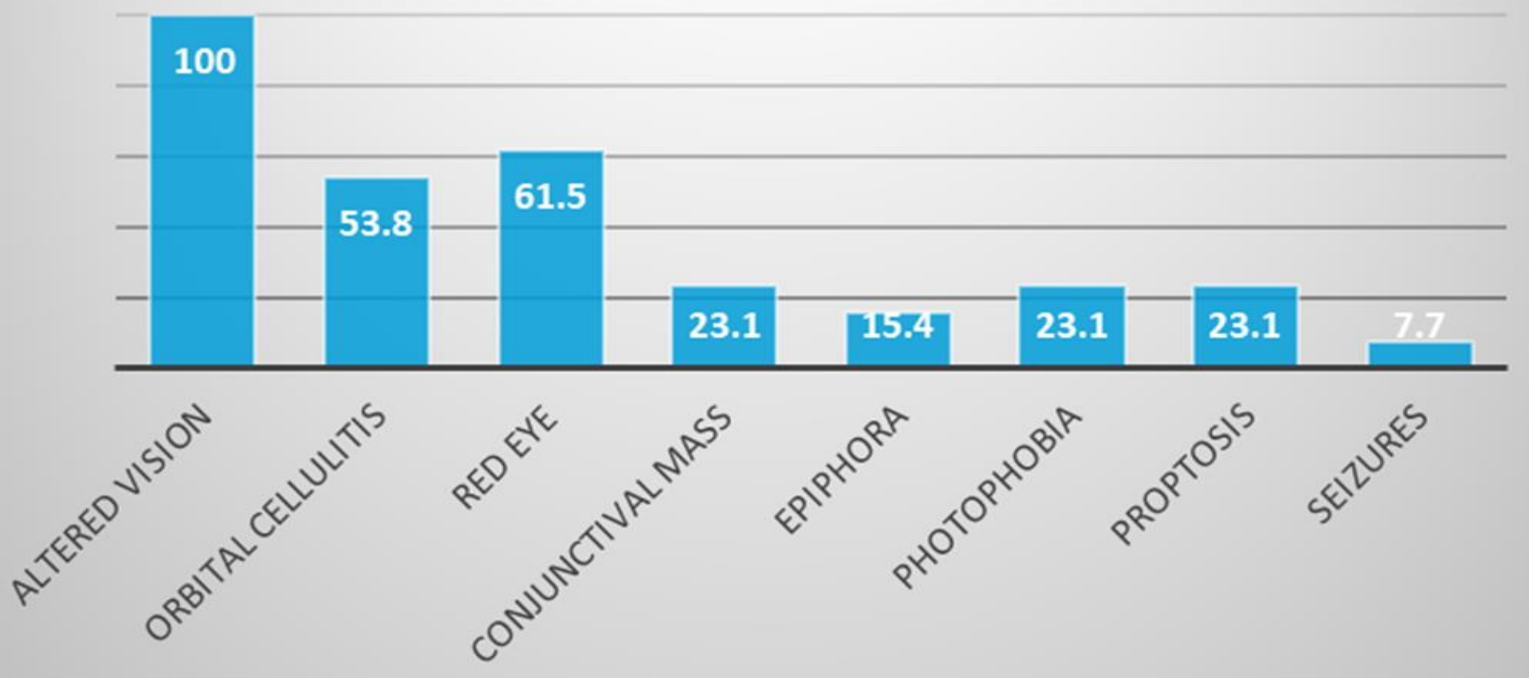

Figure 4. Clinical features of retinoblastoma $(n=49)$

\section{Clinical features of other ocular cancers}

Among paediatric patients with other ocular cancers, altered vision $13(100 \%)$ and red eye 8
$(61.5 \%)$ were the predominant clinical features and the least reported ones were epiphora $(15.4 \%)$ and seizures $(7.7 \%)$. (Figure 5$)$

\section{Frequency (\%)}

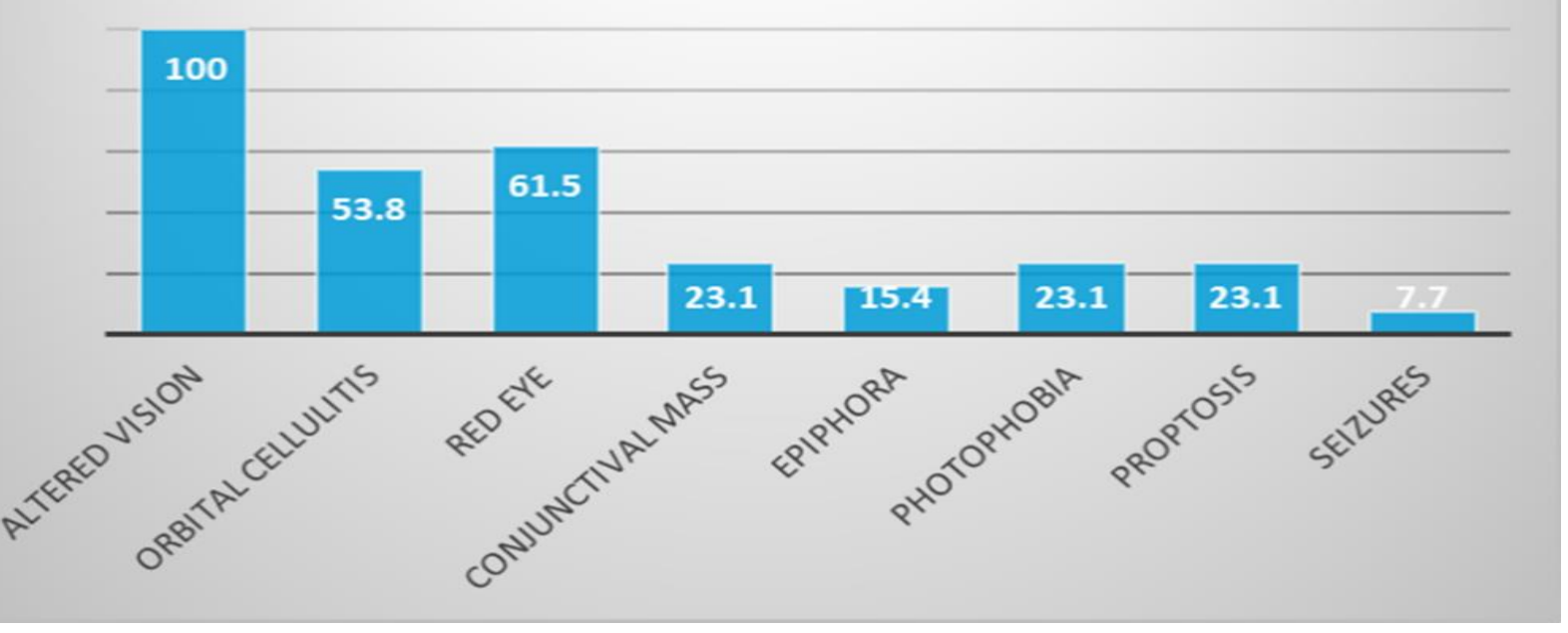

Figure 5. Clinical features of other ocular cancers $(n=13)$ 
Rwanda Journal of Medicine and Health Sciences Vol.3 No.1 March 2020 https://dx.doi.org/10.4314/rjmhs.v3i1.3

Clinical features of paediatric aural and skin cancers

From the study, otorrhoea, aural mass, otalgia, hearing loss, facial nerve palsy and deformed ears were equally reported in $100 \%$ of patients with aural cancers. For skin cancers, neck masses predominated in $6(85.7 \%)$ of cases and none had distant metastasis. (Table 3)

Table 3: Clinical features of paediatric aural and skin cancers

\begin{tabular}{ll}
\hline Clinical features & Frequency (\%) \\
\hline Aural cancer (n=6) & $6(100)$ \\
Otorrhoea & $6(100)$ \\
Aural mass & $6(100)$ \\
Otalgia & $6(100)$ \\
Hearing loss & $6(100)$ \\
Facial nerve palsy & $6(100)$ \\
Deformed ears & \\
Skin cancer $(\mathbf{n}=\mathbf{7})$ & $2(28.6)$ \\
Scalp masses & $6(85.7)$ \\
Neck masses & $4(57.1)$ \\
Cranial nerve deficits & $0(0)$ \\
Distant metastasis & $1(14.3)$ \\
Facial skin lesions & \\
\hline
\end{tabular}

Clinical features of oral cavity cancers, cervical neuroblastoma and parapharyngeal space cancer

Patients with oral cavity cancers had palatal mass, difficulty in breathing and ulcerative lip mass each accounting for $33.3 \%$ of cases. Cervical neuroblastoma had equal predominance of the reported features similar to parapharyngeal space cancer. (Table 4)

Table 4. Clinical features of oral cavity cancers, cervical neuroblastoma, jaw sarcomas and parapharyngeal space cancer

\begin{tabular}{ll}
\hline Clinical features & Frequency (\%) \\
\hline Oral cavity cancer (n=2) & $1(50)$ \\
Palatal mass & $1(50)$ \\
Difficulty in breathing & $1(50)$ \\
Ulcerative lip mass & \\
Cervical neuroblastoma (n=1) & $1(100)$ \\
Weight loss & $1(100)$ \\
Fevers & $1(100)$ \\
Neck mass & $1(100$ \\
Night sweats & \\
Parapharyngeal space cancer $(\mathbf{n = 1})$ & $1(100)$ \\
Dysphagia & $1(100)$ \\
Difficulty in breathing & $1(100)$ \\
Intraoral swelling & $1(100)$ \\
Neck mass &
\end{tabular}




\section{DISCUSSION}

To the best of our knowledge, this is the first study to characterize the clinical features for paediatric head and neck cancers in Tanzania and subSaharan Africa region at large. These findings also were aimed to provide important baseline data which can be compared with results from other countries and also to alert clinicians about such cancers so that they are diagnosed appropriately and enable their referral to designated oncological centers since they are potentially lethal by virtue of their anatomical location.

Findings in this study depict the same clinical profile as it has been found in several other studies from different parts of the world. Majority of studied participants were in the age group 0-5 years. Males outnumbered females in this study with male to female ratio being 1.6:1 ( $p=0.002)$ with mean age at encounter being $1.64 \pm 0.8$ years. Such findings correlate with those from Nigeria, Ghana, Iran and India.[7-10]

From this study, the commonest affected anatomical site was the neck (cervical node) followed by the orbit and lastly parapharyngeal space and oral cavity similar to findings of studies done elsewhere. $[9,11,12]$ Such similarity may be accounted for by almost similar strata of the studied individuals where the ages correspond epidemiologically to life time incidence of paediatric head and neck cancers.

The various clinical features for pediatric head and neck cancers at MNH are as discussed hereunder.

This study has found leukocoria, red eye, orbital cellulitis, proptosis, altered vision and strabismus to be the commonly encountered clinical features of retinoblastoma. Such findings correlate closely to other studies done elsewhere which reported leukocoria followed by strabismus $[13,14]$ or proptosis $[15,16]$ to be the prominent features. Other features such as orbital cellulitis, altered vision, buphthalmos have also been reported in the studies under comparison. The observed similarity may be accounted for by natural history of retinoblastoma thus yielding similar clinical presentation.

Nasal obstruction, epistaxis and rhinorrhoea were among the commonest clinical features of sinonasal cancers in this study and such findings were similar to what has been documented in studies done elsewhere.[17-19] Other clinical features of sinonasal cancers at MNH have been also reported in almost similar fashion to the studies under comparison.
This study elucidated rhinological (nasal obstruction, epistaxis), otological (hearing loss, otalgia) features and neck masses to be the commonest clinical features of nasopharyngeal cancer. These findings appear to be in line with what has been reported in other studies.[20-23] The observed similarity may be attributed by the stage at which patients may have presented to health facilities and having their clinical features characterized.

Fevers, weight loss and neck masses have been reported to be the commonest clinical features among patients with non-Hodgkin lymphoma and Hodgkin lymphoma in this study. Similar findings can also be depicted from studies done elsewhere.[24-26] Such similarity may be due to shared aetiopathogenesis of lymphomas despite variable geographical presentation.

Malignant parapharyngeal space neoplasms in paediatric patients have been reported in rarity from the reviewed literatures and this correlate to what has been established in this study from MNH where such cancer has been one of the least common neoplasms. One study from Egypt reported paediatric patients with malignant parapharyngeal space lesions to exhibit the following clinical features; slowly progressive neck swelling, intraoral swelling, pressure symptoms such as stridor and dysphagia, six and seventh cranial nerve palsies. Such findings from Egypt correlate closely with those reported in this study.[27]

\section{CONCLUSION}

To the best of our knowledge, this is the first study to document the clinical profile of paediatric head and neck cancers in Tanzania and sub-Saharan Africa and the findings represented in this study demonstrate similarity with those from other countries. Clinicians should have a high index of suspicion when encountering paediatric patients with head and neck cancers so that they are diagnosed at early stage and enable their referral to designated oncological centers where such patients do receive prompt treatment and therefore spearheading the fight against paediatric morbidity and mortality.

\section{RECOMMENDATION}

A large multicentric study on paediatric head and neck malignant neoplasms should be designed in our country by involving other referral hospitals with paediatric oncology units so as to have a national framework on such neoplasms as it will direct resource allocation bearing in mind that these neoplasms are deleterious through their ability to 
interfere with vital functions of life. In addition, health care providers should carefully handle paediatric patients with neck masses to rule out the possibility of any malignant neoplasm.

\section{Acknowledgement}

The University of Dodoma is highly acknowledged for financial support and also $\mathrm{MNH}$ for provision of a conducive environment for conducting the study.

\section{Conflict of interest}

\section{None}

\section{Authors' contribution}

All authors have contributed in preparation of this article.

This article is published open access under the Creative Commons Attribution-

NonCommercialNoDerivatives (CC BYNC-ND4.0). People can copy and redistribute the article only for noncommercial purposes and as long as they give appropriate credit to the authors. They cannot distribute any modified material obtained by remixing, transforming or building upon this article. See

https://creativecommons.org/licenses/by-ncnd/4.0/

\section{REFERENCES}

1. Adisa AO, Adeyemi BF, Oluwasola AO, Kolude B, Akang EE, Lawoyin JO. Clinico-pathological profile of head and neck malignancies at University College Hospital, Ibadan, Nigeria. Head \& face medicine. $2011 \mathrm{Dec} ; 7(1): 9$.

2. Pai SI, Westra WH. Molecular pathology of head and neck cancer: implications for diagnosis, prognosis, and treatment. Annual Review of Pathological Mechanical Disease. 2009 Feb 28;4:4970.

3. Adeyemo A, Okolo C. Pediatric head and neck malignancies in sub-Saharan Africa. Journal of Pediatric Sciences. 2012 Oct 10;4(4):1-9.

4. Chadha NK, Forte V. Pediatric head and neck malignancies. Current opinion in otolaryngology \& head and neck surgery. 2009 Dec 1;17(6):471-6.

5. Gilyoma JM, Rambau PF, Masalu N, Kayange NM, Chalya PL. Head and neck cancers: a clinicopathological profile and management challenges in a resource-limited setting. BMC research notes. 2015 Dec;8(1):772.

6. Albright JT, Topham AK, Reilly JS. Pediatric head and neck malignancies: US incidence and trends over 2 decades. Archives of Otolaryngology-Head \& Neck Surgery. 2002 Jun 1;128(6):655-9.

7. Khademi BI, Mahmoodi JA, Omidvari SH, Mohammadianpanah MO. Treatment results of nasopharyngeal carcinoma: a 15-year single institutional experience. J Egypt Natl Canc Inst. 2006 Jun 15;18(2):147-55.

8. Shehu UA, Adegoke SA, Abdulsalam U, Ibrahim M, Oyelami OA, Adeodu OO. Pattern of childhood malignant tumours in two tertiary teaching hospitals in Nigeria: comparative Study. Nigerian Journal of Paediatrics. 2013;40(2):175-8.

9. Shojaei S, Zargaran M, Baghaei F, Farhadifar H, Dehbani Z, Faradmal J, Sedighi A, Dehghan A, MONSEF EA, Jafari M. Frequency of head and neck cancers in children and adolescents in an Iranian population from 1989 to 2009.

10. Chukwu BF, Ezenwosu OU, Ikefuna AN, Emodi IJ. A prospective study of childhood malignancy in Enugu, Eastern Nigeria (2011-2013). Nigerian Journal of Paediatrics. 2015;42(2):116-20.

11. Khademi B, Taraghi A, Mohammadianpanah M. Anatomical and histopathological profile of head and neck neoplasms in Persian pediatric and adolescent population. International journal of pediatric otorhinolaryngology. 2009 Sep 1;73(9):1249-53.

12. Abraham ZS, Kahinga AA, Swai H, Massawe ER. Clinico-histocytopathological profile of paediatric head and neck malignant neoplasms: a mini-review. Medical Journal of Zambia. 2018;45(2):82-91

13. Chuluunbat $T$, Jamiyanjav $B$, Munkhuu $B$, Bazarsad U, Molom A, Kao LY, Wu WC. Retinoblastoma in Mongolia: Clinical characteristics and survival from 1987 to 2014 . Taiwan journal of ophthalmology. 2016 Jun 1;6(2):79-84.

14. El Zomor H, Nour R, Alieldin A, Taha H, Montasr MM, Moussa E, El Nadi E, Ezzat S, Alfaar AS. Clinical presentation of intraocular retinoblastoma; 5-year hospital-based registry in Egypt. Journal of the Egyptian National Cancer Institute. 2015 Dec 1;27(4):195-203.

15. Essuman V, Ntim-Amponsah CT, Akafo S, Renner L, Edusei L. Presentation of retinoblastoma at a paediatric eye clinic in Ghana. Ghana medical journal. 2010;44(1).

16. Chawla B, Hasan F, Azad R, Seth R, Upadhyay $\mathrm{AD}$, Pathy S, Pandey RM. Clinical presentation and survival of retinoblastoma in Indian children. British Journal of Ophthalmology. 2016 Feb $1 ; 100(2): 172-8$.

17. Fasunla AJ, Lasisi AO. Sinonasal malignancies: a 10-year review in a tertiary health institution. Journal of the National Medical Association. 2007 Dec;99(12):1407.

18. Koivunen $P$, Mäkitie AA, Bäck L, Pukkila M, Laranne J, Kinnunen I, Aitasalo K, Grénman R. A national series of 244 sinonasal cancers in Finland in 1990-2004. European Archives of Oto-RhinoLaryngology. $2012 \mathrm{Feb}$ 1;269(2):615-21. 
19. Opoku-Buabeng J, Acquah S. Clinical and histopathological presentations of sinonasal cancers in KomfoAnokye Teaching Hospital. ENT Updates. 2016 Aug 1;6(2):87.

20. Oladipo O, Ralph AO, Ahintola BA, Babatunde B. Histopathological pattern of nasopharyngeal malignancy in Lagos University Teaching Hospital (LUTH) Lagos Nigeria. International Journal of Scientific \& Engineering Research. 2015;6(5):173347.

21. Alabi BS, Badmos KB, Afolabi OA, Buhari MO, Segun-Busari S. Clinico-pathological pattern of nasopharyngeal carcinoma in Ilorin, Nigeria. Nigerian journal of clinical practice. 2010;13(4).

22. Chang ET, Adami HO. The enigmatic epidemiology of nasopharyngeal carcinoma. Cancer Epidemiology and Prevention Biomarkers. 2006 Oct 1;15(10):1765-77.

23. Suzina SA, Hamzah M. Clinical presentation of patients with nasopharyngeal carcinoma. The Medical journal of Malaysia. 2003 Oct;58(4):539-45.
24. Yakubu M, Ahmadu BU, Yerima TS, Simon P, Hezekiah IA, Pwavimbo AJ. Prevalence and clinical manifestation of lymphomas in North Eastern Nigeria. Indian journal of cancer. 2015 Oct 1;52(4):551.

25. Mwanda OW. Clinical characteristics of Burkitt's lymphoma seen in Kenyan patients. East African medical journal. 2004 Aug (8 Suppl):S7889.

26. Choudhry VP, Agarwal RK, Marwah RK. Characteristics of Burkitt's lymphoma in India. The Indian Journal of Pediatrics. 1987 Nov 1;54(6):85962.

27. El Fiky L, Shoukry T, Hamid O. Pediatric parapharyngeal lesions: Criteria for malignancy. International journal of pediatric otorhinolaryngology. 2013 Dec 1;77(12):1955-9.

28. Mwansasu C, Liyombo E, Moshi N, Mpondo BC. Pattern of head and neck cancers among patients attending Muhimbili National Hospital Tanzania. Tanzania Journal of Health Research. 2015;17(1):16. 